\title{
Narrow Networks On The Health Insurance Marketplaces: Prevalence, Pricing, And The Cost Of Network Breadth
}

\section{Citation}

Dafny, Leemore S, Igal Hendel, Victoria Marone, and Christopher Ody. "Narrow Networks On The Health Insurance Marketplaces: Prevalence, Pricing, And The Cost Of Network Breadth." Health Affairs (Project Hope) 36, no. 9 (2017): 1606-1614.

\section{Permanent link}

http://nrs.harvard.edu/urn-3:HUL.InstRepos:39148382

\section{Terms of Use}

This article was downloaded from Harvard University's DASH repository, and is made available under the terms and conditions applicable to Open Access Policy Articles, as set forth at http:// nrs.harvard.edu/urn-3:HUL.InstRepos:dash.current.terms-of-use\#OAP

\section{Share Your Story}

The Harvard community has made this article openly available. Please share how this access benefits you. Submit a story. 


\section{Narrow Networks on the Health Insurance Marketplaces: Prevalence, Pricing and the Cost of Network Breadth}

\section{Abstract}

Anecdotal reports and systematic research highlight the prevalence of "narrow network" plans on the Affordable Care Act (ACA)'s Health Insurance Marketplaces. At the same time, marketplace premiums during 2014-2016 were much lower than projected. Using detailed data on the breadth of both hospital and physician networks, we study the prevalence of narrow networks and quantify the association between network breadth and premiums. Controlling for many potentially confounding factors, a plan with narrow physician and hospital networks is 16 percent cheaper than a plan with broad networks for both; narrowing just one is associated with a 6-9 percent decrease in premiums. Narrow-network plans also have a sizeable impact on federal outlays, as they depress the "second-lowest silver premium" linked to subsidy amounts. Holding all else constant, we estimate federal subsidies would have been 10.8 percent higher in 2014 had marketplaces required all plans to offer broad provider networks. Narrow networks are a promising source of potential savings for other commercial insurance segments, although the long-term impacts on provider costs and viability remain unknown. 


\section{Introduction}

From 1999 to 2013, employer-sponsored health insurance premiums grew at an average annual rate of 7.7 percent, 4.7 percent faster than the average annual rate of growth in US GDP per capita.(1)(2) Premiums for plans offered through the public marketplaces, which were first introduced in 2014, were projected to grow at similar rates.(3) However, from 2014-2016, both premium levels and growth rates for marketplace plans were substantially lower than expected. For example, Adler and Ginsburg (2016) estimate that premiums for benchmark ("second lowest silver") plans in 2014 were 15 percent below the Congressional Budget Office's (CBO's) 2009 projections. By 2016 these premiums were 20 percent below CBO's 2009 projections, reflecting slower growth rates.(4)

Marketplace premiums may have been lower than projected for a number of reasons, such as different expectations about the underlying health risk of enrollees and strategic underpricing by insurers seeking to attract enrollees with low premiums and then "harvest" profits through higher premiums in subsequent years.(5) Indeed, marketplace premiums appear to have spiked upwards in 2017, although part of this spike is attributable to the expiration of two of the three programs to curb insurer risk (i.e., reinsurance and risk corridors; risk-adjustment remains). 
In this study, we focus on the contribution of reduced breadth of provider networks to lower premiums.

Several recent studies document a high prevalence of narrow network plans on the marketplaces.(6) (7) For example, McKinsey's Center for U.S. Health System Reform (hereafter, McKinsey) reports that roughly 40 percent of hospital networks on the marketplaces in 2014, 2015, and 2016 were comprised of less than 70 percent of hospitals in a given geographic area. (8) Physician networks are even narrower than hospital networks. Polsky et al. (2016) reports that the average marketplace network contains just 30 percent of local market physicians in $2014 \cdot(9)$

There are three primary mechanisms through which this shift to narrow provider networks may be contributing to lower premiums. First, insurers may realize lower total medical spending by identifying and contracting only with providers who are "efficient" - that is, who agree to low reimbursement rates or who generate medical savings by performing only necessary services and utilizing the lowest-cost, appropriate sites of care for those services).(10) In their 2016 study of the impact of narrow network plans on spending and utilization, Gruber and McKnight (2016) find evidence consistent with this hypothesis. State employees induced by a "premium holiday" to join a narrow network plan increased (arguably efficient) primary care 
spending and decreased (arguably inefficient) specialist spending; when these effects were combined, the narrow network plan reduced overall medical spending by 40 percent. (11) (Notably, Haeder et al. (2015) find that narrow does not necessarily mean low-quality: the average marketplace plan in California included fewer hospitals than the average commercial plan, but the average quality of in-network hospitals was not measurably lower. (12))

Second, narrow-network plans may be able to negotiate lower prices from providers in return for steering more patient volume to them, and then pass these savings on to consumers in the form of lower premiums. Third, the threat of exclusion should motivate providers to become more efficient - which in turn should reduce total medical expenditures and therefore premiums.

To date, researchers have not provided a definitive answer to the question of how much cheaper are narrow-network plans. Mckinsey reports that among silver plans on the marketplaces in 2014, plans with narrow hospital networks were priced 16 percent below "similar" plans with broad hospital networks, and this discount rose to 22 percent by 2016.(8) (13) Polsky et al. (2016) report that among silver plans on the marketplaces in 2014, those with "extra-small" physician networks were priced 6.7 percent below "similar" silver plans with "large" physician networks in 2014. There are a number of potential explanations 
for these substantially different magnitudes, such as the distinction between physician and hospital networks, and how "similar" plans are defined, underscoring the need for further research.

This study makes a number of contributions beyond prior research, including a related study by Dafny et al. 2015, described below. We consider the effect of both hospital network breadth and physician network breadth on premiums, whereas prior studies have only analyzed one network type at a time. We also construct a more accurate measure of hospital network breadth: rather than taking a count of in-network hospitals in an area, we weight the importance of in-network hospitals based on the volume of inpatient stays at each network hospital by residents of the relevant geographic market. Thus, more popular, conveniently-located, and larger hospitals "count more" in our measure. This is the same measure used in Dafny et al. (2015), but that study used just one state (Texas) and one year of data (2014), whereas our data spans eight states including 43 percent of the U.S. population.

While other papers have examined the relationship between breadth and premiums, we estimate how narrow network plans have influenced the level of federal subsidies in the marketplaces. We also estimate the impact of narrow-network plans on federal outlays by using our model to predict premiums if all hospital 
and physician networks in the eight states we study were required to be "broad" and "large," respectively.

\section{Study Data and Methods}

\section{Data resume}

We obtained data from the Robert Wood Johnson Foundation (RWJF) on all silver-tier health insurance plans offered on the marketplaces in every "rating area" in 2014 and/or 2015 in eight states, California, Colorado, Florida, Michigan, New Jersey, New York, Texas, and Washington (hereafter, the "Sample States").) (14) The Sample States contain roughly 43 percent of the US population and span different marketplace governances. (15) Silver-tier plans cover about 65 percent of marketplace enrollees, but include virtually all of the unique provider networks that are offered on the exchanges.(16)(17)(18) A rating area is the most granular level of geography at which insurers can vary premiums. The RWJF dataset includes each plan's type (i.e., HMO, PPO, EPO, POS), medical out of pocket maximum, medical in-network deductible, and the premium for a single 27-year-old. Because premiums are multiplied by a common factor to adjust for family size and age, analyses using the natural log of premiums - such as the regression analysis we describe below - will yield the same results for any hypothetical household. (19) 
During the summer of 2014 and winter of 2014-2015, our research staff visited insurers' web sites to collect the names and addresses of all general acute care hospitals included in the hospital network of each plan on the relevant marketplace, for 2014 and 2015, respectively. We matched hospitals based on these names and addresses to discharge datasets from each state. This sample of hospitals makes up the universe of hospitals we considered in constructing our measure of hospital network breadth.

The hospital discharge data, which we obtained for a single recent year for all eight states, enabled us to construct a utilization-weighted measure of breadth, rather than relying on simple counts of hospitals. We defined "hospital network breadth" for a network in a given rating area to be the number of discharges for patients living in the rating area that occur at "in-network" hospitals divided by the total number of discharges for patients living in the rating area.(20) We imposed a number of sampling restrictions on the discharge datasets when constructing our measure - e.g., limiting to patients aged 18-64 discharged from general acute care hospitals; details are available in the Data Appendix. (21)

We used the physician network breadth measure developed and posted by Polsky et al. (2016). This measure of physician network breadth, available for 85 percent of silver plans in 
2014 only, is defined as the number of in-network physicians in a rating area divided by the total number of physicians in the rating area.

Methods

We used observational data to explore the impact of narrownetwork plans on marketplace premiums and federal premium subsidies. We lack a quasi-experimental design, so our results are suggestive rather than conclusive. However, we gathered and controlled for a large set of factors that jointly impact both network breadth and premiums, so as to reduce the potential sources of bias in our estimates. To aid us in that endeavor, we began by analyzing statistics on the prevalence of narrow network plans and the factors correlated with network breadth. Next, we examined the relationship between network breadth (for both hospitals and physicians) and premiums using multivariate regressions. The goal of these analyses was to understand how network breadth affects premiums holding all else equal. Such estimates allowed us to consider (under admittedly stylized assumptions) alternative scenarios, such as the impact on premiums if all insurers offered full network products. Of course, plans with different network breadths may differ in a number of other ways as well, including cost-sharing characteristics (e.g., deductible and coinsurance rates), plan 
type (e.g., HMO versus PPO), reputation of the insurance carrier, and utilization patterns and costs in the relevant rating area. Failing to account for these other factors can produce misleading estimates - for example, if network breadth tends to be lower in urban areas, and average prices are lower in these areas as well, then the link between narrowness and premiums will be overstated.

In deciding how to control for potentially confounding factors, we faced a trade-off between omitting potentially important controls, and including so many that our estimates ultimately rely upon a very small share of the data. At the first extreme, we might have included cross-sectional covariates to capture market, insurer, and plan characteristics, but allowed for differences in network breadth and premiums across insurers and markets to contribute to our estimates. At the second extreme, we might have added indicator variables for every rating area-insurer-plan type combination, and thus estimated the effect of network breadth on premiums using only variation within the same insurer, offering the same plan type, in the same rating area. In this case, we would be using only a small portion of the data, limiting the external generalizability of our findings .

We adopted an intermediate approach in our regression models, and included separate indicator variables for each 
insurer-plan type combination and each insurer-rating area combination. Appendix 2 presents a number of additional details explaining these selections, and includes the results of robustness tests. (21)

\section{Limitations}

As noted above, our analysis is descriptive, relying on associations between premiums and breadth measures to infer the role of network breadth in premium-setting. Although we were able to control for many factors that would generate bias in estimating the relationship of interest, we cannot establish a causal effect of changes in breadth on premiums, nor can we detect the mechanisms generating the estimate we obtain. Another limitation of our analysis is that our sample covers roughly 43 percent of U.S. states, by population, but may not be representative of the rest of the country. Appendix 3 presents additional analysis on the external generalizability of our results. (21) We note that our sample is tilted towards more populous and geographically larger states. These states contain some of the largest cities in the US, where - as we show below narrow networks are more prevalent. Thus, our summary statistics likely overestimate their prevalence nationwide.

We also caution that the marketplaces are relatively new and turbulent markets. There are a number of reasons that 
analyses using 2014-2015 data may not be predictive of trends in future years, including demand-side factors such as evolving tastes for different plan designs, supply-side factors such as changes in the number of participating insurers, and policy factors such as the magnitude of subsidies, the definition of "essential health benefits," and the presence of an individual mandate.

\section{Study Results}

Where are Narrow Networks Offered?

We begin by presenting detailed information on the markets in which narrow network plans tend to appear, the plan "types" featuring narrow networks, and the relationship between hospital and physician network breadth. We stratify our data across four characteristics of markets or plans: rating area population, plan type, whether a plan affects federal subsidies (i.e., is one of the two lowest priced plans), and year (2014 or 2015). For each of these characteristics, Exhibit 1 reports the mean and median of network breadth, as well as the share of networks which are "full," i.e., include all providers. We present these statistics for both hospital and physician network breadth, noting that physician network breadth is only available in 2014 .

Panel 1 groups plans based upon quartiles of the population in the rating area in which they are offered, and reveals that 
both hospital and physician networks are much broader in less populous markets than in more populous markets. For example, 58 percent of networks contain all hospitals (are "full") in the least populous markets, but only 5 percent of networks contain all hospitals in the most populous markets. The same pattern is present for mean and median network breadth. The negative correlation between market size and network breadth is perhaps unsurprising, as there may be too few providers in smaller markets to enable an insurer to exclude many of them and still satisfy network adequacy requirements or attract a sufficient number of enrollees to render such an offering profitable.

Panel 2 reveals that more heavily managed plans (i.e., HMO, EPO, and POS plans) have narrower hospital networks than do PPO plans. For example, the mean hospital network breadth for is 0.86 for PPOs, but is only 0.75 for HMOs.

Moving to Panel 3 , we see that the $1^{\text {st }}$ and $2^{\text {nd }}$ lowest priced plans in a rating area (which determine federal premium subsidies) tend to have narrower hospital networks than higher priced plans, but do not appear to have narrower physician networks. Last, Panel 4 shows some limited evidence that hospital networks grew narrower between 2014 to 2015: the share of "full" networks decreased from 37 to 27 percent, but median network breadth declined only slightly. This finding contrasts with reports of sharply heightened narrowness on the exchanges, 
at least between 2014 and 2015.(22)(23) Those reports might reflect increasing enrollment in narrow network plans over time; our descriptive statistics are not enrollment-weighted because the U.S. Department of Health and Human Services has not released plan-rating area level enrollment data.

We also note that hospital networks are, in general, much broader than physician networks. Physician networks are almost never full, and the distribution of breadth is not as skewed to the right. As a result, while research on hospital network breadth tends to emphasize "narrow" versus "full" networks, Polsky et al.'s research on physician network breadth utilizes "t-shirt size" categories to capture finer gradations in network breadth.

Exhibit 2 presents a scatter plot of both measures of network breadth, where each point represents the breadths associated with a unique plan-rating area combination. The correlation coefficient ( $r$ ) between hospital and physician network breadth is 0.25 , which indicates that $6.25 \%$ of the variation in each can be explained by a linear relationship with the other (i.e., r-squared=0.0625).(24) The positive correlation implies that regression models excluding either measure will likely overstate the effect of the included measure. The fact that the points are not neatly arrayed along a line (i.e., the correlation coefficient is far from 1.0) implies that it should 
be possible to isolate the independent association of each measure (holding the other constant) with premiums, as they do not always move in tandem.

Relationship between Network Breadth and Premiums

We next examine the relationship between network breadth and premiums. The dependent variable in the regression analysis is the natural log of premiums; this transformation allows us to interpret the resulting coefficients as (approximate) percentage changes in premiums (Appendix 3, Exhibit A3.3 confirms that the results are similar if we instead use unlogged premiums as the dependent variable).(21) We estimated three regression models for 2014: one including hospital breadth, a second including physician network breadth, and a third including both; we also estimated a regression for 2015 using hospital network breadth alone. All specifications are weighted, so that plans in more populous areas - which have a larger effect on federal subsidy outlays and are likely to have higher enrollment - have a greater impact on the estimates. (25)

Exhibit 3 presents estimated premium changes in response to increases in network size for the 2014 model that included both hospital and physician network breadth measures. Both hospital and physician breadth are positively and significantly 
associated with premiums. Using the results from our preferred regression analysis (which is presented in Exhibit A3.1, column (3)), we estimate that an increase in hospital network breadth from 0.7 (the McKinsey definition of "narrow") to 1.0 (a "full" network) is linked to a premium increase of 5.7 percent.(21) An increase in physician network breadth from "small" (corresponding to 10 percent of physicians) to "large" (corresponding to 40 percent) is linked to a premium increase of 9.4 percent. (26) An increase in both hospital network breadth to "full" and physician network breadth to "large" is linked to a premium increase of 15.7 percent. Thus, narrow physician networks are associated with larger premium decreases than narrow hospital networks. While at first blush, this result may appear surprising given the larger size of the hospital sector, for the commercially-insured, per-capita spending on outpatient visits and medications far exceeds spending on inpatient visits. (27)

Our models that included either breadth measure alone generated upward-biased estimates of their independent association with premiums, with the bias significantly larger for the model omitting hospital network breadth (results available in Exhibit A3.1) (21) .

Our analysis of 2015 data (presented in Exhibit A3.1) showed no evidence that network breadth is a more important 
determinant of premiums in 2015 relative to 2014: the estimated association between hospital network breadth and premiums has the same magnitude and statistical significance in both years (28).

We cannot quantify the impact of narrow networks on total outlays for plans sold through the marketplaces because planrating area enrollment data is not available. However, we can estimate the impact of narrow networks on federal outlays because subsidies are based on the second-lowest silver premium in each rating area, which may correspond to a plan with narrow provider networks. Indeed, as shown in Panel 3 of Exhibit 1, the lowest and second-lowest silver premium plans tend to have narrower hospital networks than higher priced plans. We used the regression model in Exhibit A3.1, column (3) to predict counterfactual premiums for each plan in 2014, substituting hypothetical requirements for a full hospital network and a "large" physician network. (21) We find that if all plans were to offer these broader provider networks, then the populationweighted average second-lowest silver premium would increase by 10.8 percent, or $\$ 330$ per year. Incorporating the Congressional Budget office's estimates of the link between the second-lowest silver premium and total subsidies, our estimate implies that narrow networks lowered premium subsidies by roughly 2.4 billion dollars in 2014.(29)(30) 
We caution that our calculation of counterfactual subsidies is highly speculative, as the correlations that we measure may not reflect a causal relationship between subsidies and provider network breadth. Furthermore, these results should not be taken as a prediction of the effects of a "broad network" mandate because such a mandate would affect provider-insurer bargaining positions in ways our model does not capture. (Given that the marketplaces are so small, this shortcoming is not as severe as it would be if the hypothetical mandate were to extend to the entire commercially-insured population, but the inability to threaten exclusion from networks could result in substantially higher prices even for this segment of the insurance market.) In addition, it's important to note that lower premiums do not necessarily imply a "better deal" for subsidy-eligible enrollees. To the extent that such plans drive the second-lowest silver premium down, they reduce subsidies for eligible exchange enrollees, and increase the out-of-pocket premium for higherpriced plans.

\section{Implications and Conclusion}

Narrow provider networks have proven to be a contentious policy topic, so as policy priorities evolve under the new administration, it is important to have realistic estimates of the premium reductions that can result from non-exhaustive 
provider networks. Our analysis of the link between premiums and provider network breadth, which controls for a wider range of potentially confounding variables than earlier studies, indicates that non-exhaustive provider networks are associated with substantial reductions in premiums. Our results provide suggestive evidence that narrow provider networks could explain much of the roughly 15 percent gap between the CBO's November 2009 premium projections and actual 2016 premiums; the other primary factor explaining the underestimate is likely the CBO's 2009 overestimate of health care cost growth. (31)

While premiums for 2014-2016 came in substantially below predictions, premiums in 2017 showed a marked increase. There are several explanations for this increase, including the expiration of the risk corridor and reinsurance programs, greater uncertainty faced by remaining insurers in the wake of exits by other insurers, the claims experience of marketplace enrollees, and the realization that marketplace enrollees are less inertial than enrollees in employer-sponsored plans, hence strategies to price low to attract enrollees and then reap profits through subsequent price increases are less appealing. (5)

We note, in closing, that narrow networks may have important spillover effects worthy of further examination. On the one hand, the popularity of low-premium plans (associated 
with narrow networks) has a positive spillover effect because it places pressure on providers within all networks to offer greater value, e.g., in the form of lower reimbursement rates or via cooperating with or developing innovative, cost-saving alternatives to fee-for-service reimbursement. Unless providers in broad networks can increase their value proposition, broad network plans may become uncompetitive and ultimately exit marketplaces.

This dynamic may lead to the premature exit of broad network plans - particularly in the marketplaces, whose enrollees are price-sensitive - if they cannot achieve competitive pricing in short order. The disparity in pricing at the outset leads only those enrollees who place a high value on broad networks to pay for broad plans, and these enrollees are likely to be in worse than average health (e.g., because they wish to retain current providers who may be excluded from a given narrow network). The result is an ever-growing disparity in average spending for enrollees in narrow vs. broad plans. Absent perfect risk-adjustment, a "death spiral" may unfold, whereby broad-network plans raise premiums to cover increasing costs, causing the healthiest of their remaining enrollees to switch to less expensive plans, raising average costs even more. As this process repeats, broad network plans could become so expensive that they are no longer offered. In fact, there are 
widespread reports that broad plans are exiting the marketplaces, likely to avoid or stanch the bleeding from costly "death spirals." (32) (33)

Although employers are embracing narrow networks more slowly than the marketplaces - presumably because decisionmakers selecting plan offerings (and employees choosing among those offerings) place a greater value on breadth than does the average marketplace enrollee - these developments may spread to the group market as well. In the years ahead, regulators and employers will want to tread carefully to enable the benefits of narrow-network plans - including the price pressure they impose on broader-network plans- while avoiding death spirals that remove broad-network plans from the set of available insurance options.

\section{Endnotes}

1. World Bank [Internet]. World Development Indicators [cited 2016 oct 10]. Available from: http://data.worldbank.org/datacatalog/world-development-indicators

2. Henry J. Kaiser Family Foundation, Health Research and Educational Trust. Employer health benefits: 2016 annual survey, Exhibit 1.13 [Internet]. Menlo Park (CA): KFF; 2016 Sep [cited 2016 Oct 10]. Available from: http://kff.org/reportsection/ehbs-2016-section-one-cost-of-health-insurance/ 3. ASPE Issue Brief. August 2013. "Market Competition Works: Silver Premiums in the 2014 Individual Market Are Substantially Lower than Expected". HHS.

4. Ginsburg, P and L Adler, Obamacare Premiums Are Lower Than You Think. July 21, 2016. [cited: 10 Oct 2016]. In: Health Affairs Blog [Internet]. Available from: http://healthaffairs.org/blog/2016/07/21/obamacare-premiums-arelower-than-you-think/ 
5. Gruber, J. Obamacare: What we didn't see coming. 2016 Jul

21 [cited: 20 Oct 2016] In: Politico. The Agenda: Obamacare [Internet]. Available from:

http://www.politico.com/agenda/story/2016/07/obamacare-what-wedidnt-see-coming-000170

6. We note that the concept of narrow networks is not a new one in all aspects of health insurance design; for example, insurers have limited access to mental health providers using "mental health panels" for a long time (See, e.g., Jacob et al.) 7. Jacob V, Qu S, Chattopadhyay S, Sipe TA, Knopf JA, Goetzel RZ, et al. Economic Effects of Legislations and Policies to Expand Mental Health and Substance Abuse Benefits in Health Insurance Plans: A Community Guide Systematic Review. The journal of mental health policy and economics. 2015;18(1):39-48. 8. Bello J, Coe E, Lamb J. Hospital networks: Perspective from three years of exchanges. McKinsey \& Company [Internet]. 201610 oct 2016]. Available from:

http://healthcare.mckinsey.com/sites/default/files/McKinsey\%20Re form $\% 20$ Center 2016\%20Exchange\%20Networks FINAL.pdf.

9. Polsky D, Cidav Z, Swanson A. Marketplace Plans With Narrow Physician Networks Feature Lower Monthly Premiums Than Plans With Larger Networks. Health Affairs. 2016;35(10):1842-8. 10. Haeder SF, Weimer DL, Mukamel DB. Narrow networks and the affordable care act. JAMA. 2015;314(7):669-70. 11. Gruber J, McKnight R. Controlling Health Care Costs through Limited Network Insurance Plans: Evidence from Massachusetts State Employees. American Economic Journal: Economic Policy. $2016 ; 8(2): 219-50$.

12. Haeder SF, Weimer DL, Mukamel DB. California hospital networks are narrower in marketplace Than In Commercial Plans, But Access And Quality Are Similar. Health Aff (Millwood). $2015 ; 34(5): 741-8$.

13. "Similar" here means that they have the same insurer, same rating area, and same plan type.

14. Robert Wood Johnson Foundation. HIX Compare [Internet]. Princeton (NJ): RWJF; [cited 2016 Oct 10]. Available from: http://www.rwjf.org/en/library/collections/hix-compare.html 15. California, New York, Colorado, and Washington operate state-based health insurance exchanges, while Florida, New Jersey, Michigan, and Texas operate a Federally Facilitated Marketplace.

16. CMS.gov. March 31, 2016 Effectuated Enrollment Snapshot [Internet]. [cited 2016 Oct 10]. Available from:

https://www.cms.gov/Newsroom/MediaReleaseDatabase/Factsheets/2016-Fact-sheets-items/2016-06-30.html

17. U.S. Department of Health Human Services. Health insurance marketplace: Summary enrollment report for the initial annual 
open enrollment period (October 1, 2013-March 31, 2014). ASPE Issue Brief [Internet]. 201410 Oct 2016]. Available from: https://aspe.hhs.gov/sites/default/files/pdf/76876/ib 2014Apren rollment.pdf.

18. CMS.gov. March 31, 2015 Effectuated Enrollment Snapshot [Internet]. [cited 2016 Oct 10]. Available from:

https://www.cms.gov/Newsroom/MediaReleaseDatabase/Factsheets/2015-Fact-sheets-items/2015-06-02.html

19. CCIIO. Februrary 13, 2017. State Specific Age Curve Variations. [internet]. [cited 2017 Mar 29]. Available from: https://wWw.cms.gov/CCIIO/Programs-and-Initiatives/HealthInsurance-Market-

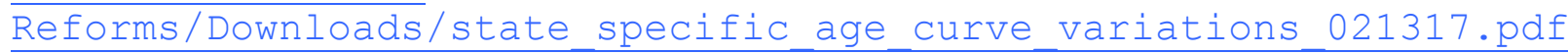
20. For plans only offered in a subset of counties within a ratings area, we construct the network breadth using data for residents in those counties. Note that hospitals outside a given ratings area may be in-network for residents of that area. 21. To access the Appendix, click on the Appendix link in the box to the right of the article online.

22. Leys, Tony. Wellmark trims broad-network health insurance options, The Des Moines Register, September 27, 2016/ [cited: 20 oct 2016]. Available From:

http://www.desmoinesregister.com/story/news/health/2016/09/27/we llmark-trims-broad-network-health-insurance-options/91184774/ 23. Japsen, Bruce. "Half Of Obamacare Choices Are HMOs Or Narrow Network Plans", Forbes. Jan 13, 2016. [cited: 20 oct 2016]. Available From:

http://www.forbes.com/sites/brucejapsen/2016/01/13/half-ofobamacare-choices-are-hmos-or-narrow-network-plans/\#678935d241b7 24. University of Pennsylvania's Leonard Davis Institute of Health Economics. LDI's National Database of Physician Networks in 2014 Marketplace Plans [Internet]. Philadelphia (PA): LDI; [cited 2016 Dec 22]. Available from:

http://ldi.upenn.edu/narrow-networks-project

25. This weighing decision does not substantively affect our results. For example, in Column (3) of Exhibit A3.1, the coefficient on hospital network breadth decreases by 10 percent and the coefficient on physician network breadth increases by 9 percent if we do no weight.

26. A shift from "narrow" to "broad" corresponds to a shift from the 28th to the 63rd percentile of the distribution for hospital networks in 2014. A shift from "small" to "large" corresponds to a shift from the 19th to the 68th percentile of the distribution for physician networks in 2014. 27. HCCI. 2015 Health Care Cost and Utilization Report. [Internet]. November 2016. [cited: 22 Dec 2016]. 
http: //www.healthcostinstitute.org/wp-

content/uploads/2016/12/2015-HCCUR-11.22.16.pdf

28. The 2014 coefficient on hospital breadth in a regression

including all observations (even those lacking physician network breadth) is very similar to that reported in the text $(0.20$ versus 0.23), hence the specifications in columns (1) and (4) are comparable.

29. Burke A, Misra A, Sheingold S. Premium Affordability, Competition, and Choice in the Health Insurance Marketplace, 2014. ASPE Research Brief [Internet]. 201410 Oct 2016].

Available from:

https://aspe.hhs.gov/sites/default/files/pdf/76896/2014MktPlaceP remBrf.pdf.

30. ASPE. Health Insurance Marketplaces 2015 Open Enrollment Period: March Enrollment Report. ASPE Research Brief

[Internet]. 2015 [cited: 10 Oct 2016]. Available from:

ttps://aspe.hhs.gov/sites/default/files/pdf/83656/ib_2015mar_enr ollment.pdf.

31. Congressional Budget Office, Updated Estimates of the Effects of the Insurance Coverage Provisions of the Affordable Care Act [Internet]. 2014 Apr [cited 2016 oct 10]. Available from: https://www.cbo.gov/sites/default/files/113th-congress2013-2014/reports/45231-acaestimates.pdf

32. Shepard M. Hospital network competition and adverse selection: Evidence from the massachusetts health insurance exchange. National Bureau of Economic Research; 2016.

33. Newkirk, Vann R., "The Vexing Economics of Obamacare", The Atlantic [Internet], Sepember 17, 2016 [cited: 03 Mar 2017]. Available From:

https://www.theatlantic.com/business/archive/2016/09/obamacarehealth-reform-insurance-economics/500348/.

\section{Exhibit List}

EXHIBIT 1 (figure)

Title: Hospital and Physician network breadth by market and plan characteristics

Sources: RWJF plan data, Penn LDI physician network data, hospital network data, and state hospital discharge datasets for FL (2011), NY (2011), CA (2012), TX (2011), MI (2014), CO

(2011), NJ (2010), and WA (2010).

Notes: Physician network breadth data is only available in 2014.

EXHIBIT 2 (figure)

Title: Hospital network breadth versus physician network breadth 
Sources: Sources: RWJF plan data, Penn LDI physician network data, hospital network data, and state hospital discharge datasets for FL (2011), NY (2011), CA (2012), TX (2011), MI (2014), CO (2011), NJ (2010), and WA (2010).

Notes: The figure includes only 2014 observations for which physician network information was available, roughly 85\% of our 2014 observations.

EXHIBIT 3 (figure)

Title: Sensitivity of Premiums to Network Breadth, 2014 Sources: RWJF plan data, Penn LDI physician network data, hospital network data, and state hospital discharge datasets for FL (2011), NY (2011), CA (2012), TX (2011), MI (2014), CO (2011), NJ (2010), and WA (2010).

Notes: Results are presented for the model including both hospital and physician network breadth measures. Percent changes shown are associated with: shift of hospital network breadth alone from "narrow" (0.7) to "full" (1.0), physician network breadth alone from small (0.1) to large (0.4), and both hospital and physician networks simultaneously. Percent changes in premiums are calculated from regression results as $100 \mathrm{x}$ $\left.\operatorname{Exp}\left[\mathrm{Bi}{ }^{\mathrm{d}}\right]-1\right)$ where $\mathrm{Bi}$ is the coefficient on the relevant network breadth measure and $d$ is the change in network breadth described above for hospitals and physicians (in the case of simultaneous change, the exponentiated term is the sum of the products of the individual coefficients and the change in network breadth). All results are statistically significant at the 0.01 level. Regression coefficients and other statistics for this model as well as separate models using only hospital network breadth and only physician network breadth, and a model using 2015 data are available in the appendix. 
Exhibit 1: Hospital and Physician network breadth by market and plan characteristics

\begin{tabular}{|c|c|c|c|c|c|c|}
\hline \multirow[b]{2}{*}{ Market or Plan Characteristic } & \multicolumn{3}{|c|}{ Hospital Network Breadth } & \multicolumn{3}{|c|}{ Physician Network Breadth } \\
\hline & $\begin{array}{c}\text { Mean } \\
\text { Networ } \\
\text { k } \\
\text { Breadt } \\
\text { h } \\
\end{array}$ & $\begin{array}{c}\text { Median } \\
\text { Networ } \\
\text { k } \\
\text { Breadt } \\
\text { h } \\
\end{array}$ & $\begin{array}{l}\text { Share of } \\
\text { networks } \\
\text { that are } \\
\text { "full" }\end{array}$ & $\begin{array}{c}\text { Mean } \\
\text { Networ } \\
\text { k } \\
\text { Breadt } \\
\text { h } \\
\end{array}$ & $\begin{array}{c}\text { Median } \\
\text { Networ } \\
\text { k } \\
\text { Breadt } \\
\text { h } \\
\end{array}$ & $\begin{array}{c}\text { Share of } \\
\text { networks } \\
\text { that are } \\
\text { "full" }\end{array}$ \\
\hline \multicolumn{7}{|l|}{$\begin{array}{l}\text { Panel 1: Rating Area Population } \\
\text { (millions) }\end{array}$} \\
\hline 1st quartile (0.0-0.1) & 0.91 & 1.00 & 0.58 & 0.39 & 0.46 & 0.01 \\
\hline 2nd quartile (0.2-0.3) & 0.82 & 0.97 & 0.35 & 0.33 & 0.39 & 0.00 \\
\hline 3rd quartile (0.4-1.0) & 0.76 & 0.96 & 0.21 & 0.25 & 0.22 & 0.00 \\
\hline 4th quartile (1.1-8.8) & 0.69 & 0.80 & 0.05 & 0.20 & 0.18 & 0.00 \\
\hline \multicolumn{7}{|l|}{ Panel 2: Plan Type } \\
\hline PPO & 0.86 & 0.99 & 0.30 & 0.29 & 0.27 & 0.00 \\
\hline EPO & 0.82 & 1.00 & 0.49 & 0.34 & 0.32 & 0.01 \\
\hline POS & 0.80 & 0.96 & 0.13 & 0.23 & 0.25 & 0.00 \\
\hline $\mathrm{HMO}$ & 0.75 & 0.94 & 0.22 & 0.29 & 0.28 & 0.00 \\
\hline \multicolumn{7}{|l|}{$\begin{array}{l}\text { Panel 3: Lowest priced plans vs. all } \\
\text { others }\end{array}$} \\
\hline 1st or 2nd lowest priced plans & 0.74 & 0.90 & 0.24 & 0.33 & 0.31 & 0.01 \\
\hline 3rd lowest and highest priced plans & 0.81 & 0.98 & 0.33 & 0.30 & 0.28 & 0.00 \\
\hline \multicolumn{7}{|l|}{ Panel 4: Year } \\
\hline 2015 & 0.80 & 0.97 & 0.27 & - & - & - \\
\hline 2014 & 0.81 & 0.99 & 0.37 & 0.31 & 0.28 & 0.01 \\
\hline
\end{tabular}

Sources: RWJF plan data, Penn LDI physician network data, hospital network data, and state hospital discharge datasets for FL (2011), NY (2011), CA (2012), TX (2011), MI (2014), CO (2011), NJ (2010), and WA (2010).

Notes: Physician network breadth data is only available in 2014. 
Exhibit 2: Hospital network breadth versus physician network breadth

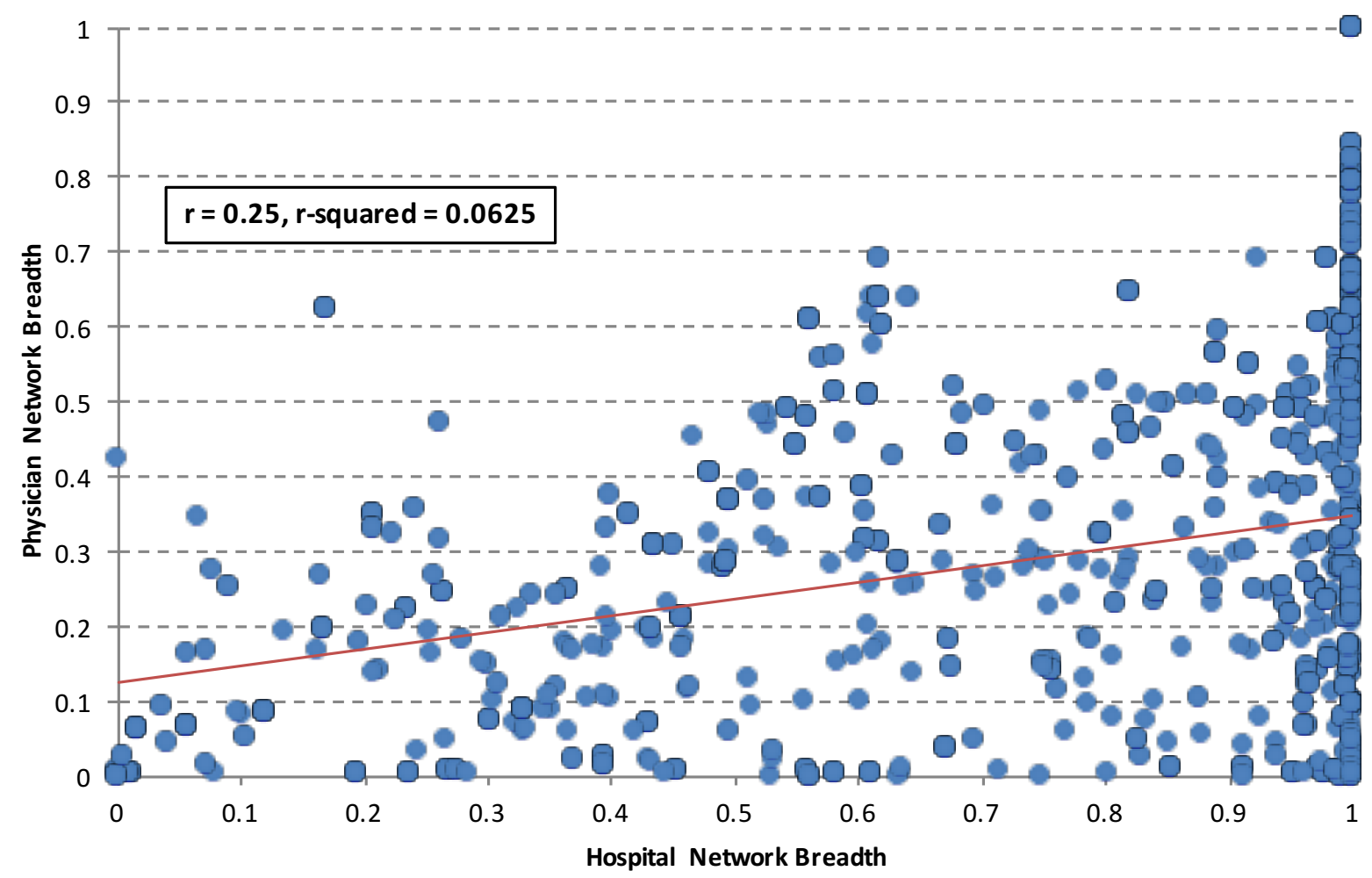

Sources: RWJF plan data, Penn LDI physician network data, hospital network data, and state hospital discharge datasets for FL (2011), NY (2011), CA (2012), TX (2011), MI (2014), CO (2011), NJ (2010), and WA (2010).

Notes: The figure includes only 2014 observations for which physician network information was available, roughly $85 \%$ of our 2014 observations. The correlation coefficient $(r)$ is 0.25 and the $r$-squared is 0.0625 . 
Exhibit 3: Sensitivity of Premiums to Network Breadth, 2014

\section{Exhibit 3: Sensitivity of Premiums to Network Breadth, 2014}

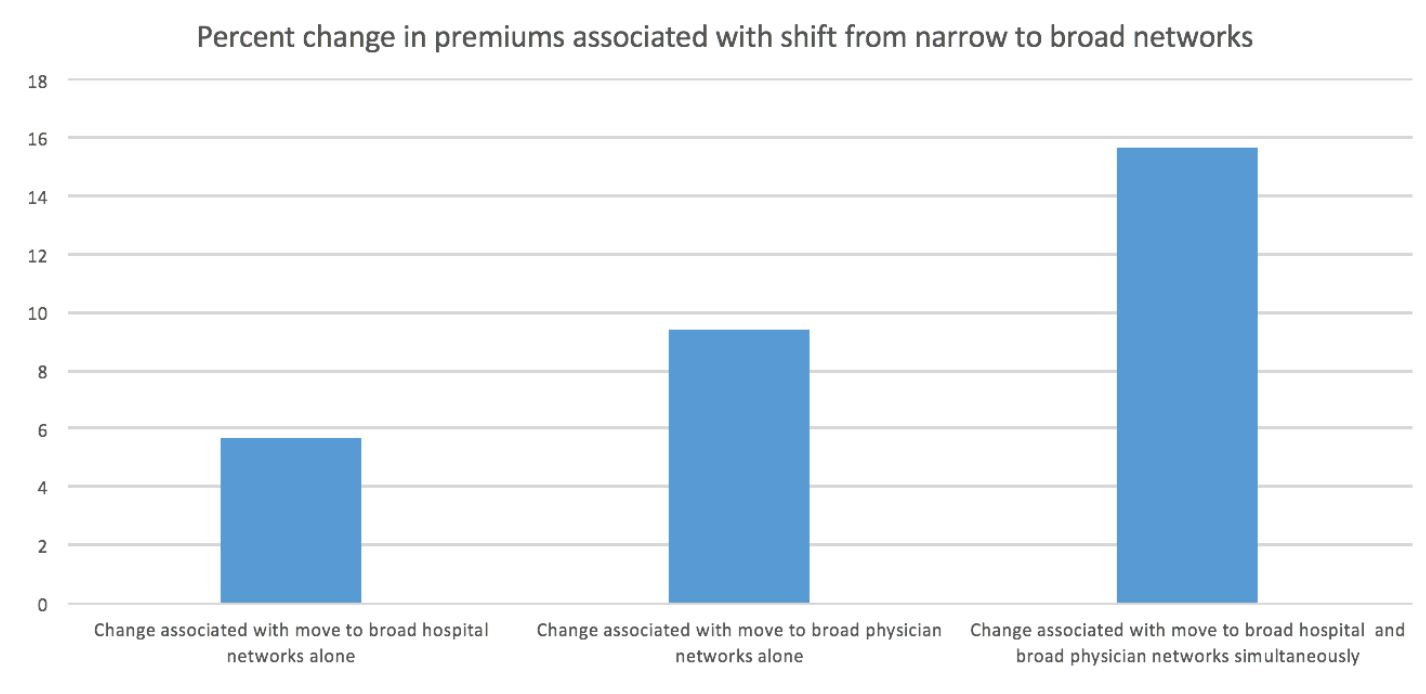

Notes: Results are presented for the model including both hospital and physician network breadth measures. Percent changes shown are associated with: shift of hospital network breadth alone from "narrow" (0.7) to "full" (1.0), physician network breadth alone from small (0.1) to large (0.4), and both hospital and physician networks simultaneously. Percent changes in premiums are calculated from regression results as $100 \mathrm{x}$ $\left.\operatorname{Exp}\left[\mathrm{Bi}^{*} \mathrm{~d}\right]-1\right)$ where $\mathrm{Bi}$ is the coefficient on the relevant network breadth measure and $\mathrm{d}$ is the change in network breadth described above for hospitals and physicians (in the case of simultaneous change, the exponentiated term is the sum of the products of the individual coefficients and the change in network breadth). All results are statistically significant at the 0.01 level. Regression coefficients and other statistics for this model as well as separate models using only hospital network breadth and only physician network breadth, and a model using 2015 data are available in the appendix.

Source: RWJF plan data, Penn LDI physician network data, hospital network data, and state hospital discharge datasets for FL (2011), NY (2011), CA (2012), TX (2011), MI (2014), CO (2011), NJ (2010), and WA (2010). 